\title{
The expression of microRNA 574-3p as a predictor of postoperative outcome in patients with esophageal squamous cell carcinoma
}

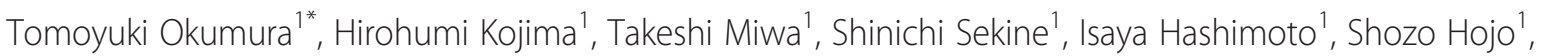
Takuya Nagata ${ }^{1}$ and Yutaka Shimada, ${ }^{1,2}$

\begin{abstract}
Background: Despite advances in radical esophagectomies and adjuvant therapy, the postoperative prognosis in esophageal squamous cell carcinoma (ESCC) patients remains poor. The aim of this study was to identify a molecular signature to predict postoperative favorable outcomes in patients with ESCC.

Methods: As a training data set, total RNA was extracted from formalin-fixed paraffin-embedded samples of surgically removed specimens from 19 ESCC patients who underwent curative esophagectomy. The expression of microRNA (miRNA) was detected using a miRNA oligo chip on which 885 genes were mounted. As a validation data set, we obtained frozen samples of surgically resected tumors from 12 independent ESCC patients and the expression of miR-574-3p was detected by quantitative real-time PCR.

Results: Our microarray analysis in the training set patients identified three miRNAs (miR-574-3p, miR-106b, and miR-1303) and five miRNAs (miR-1203, miR-1909, miR-204, miR-371-3p, miR-886-3p) which were differentially expressed between the patients with $(n=14)$ and without $(n=5)$ postoperative tumor relapse $(p<0.01$ and $p<0.05$, respectively). Higher expression of miR-574-3p, which showed the most significant association with non-relapse $(p=0.001)$, was associated with favorable overall survival $(p=0.016)$. Real-time PCR experiments on the validation set patients confirmed that higher expression of miR-574-3p was associated with non-tumor relapse $(p=0.029)$ and better overall survival $(p=0.004)$.
\end{abstract}

Conclusions: Our results suggest that the aberrant expression of the miRNAs identified in this study plays key roles in the progression of ESCC. miR-574-3p was suggested to have a tumor suppressor effect, and thus, to be a predictor of postoperative outcome in patients with ESCC.

Keywords: Esophageal cancer, Squamous cell carcinoma, miRNA, Prognostic marker, Surgery

Abbreviations: ESCC, Esophageal squamous cell carcinoma; miRNAs, MicroRNAs; FFPE, Formalin-fixed paraffinembedded; ROC, Receiver-operating characteristic; AUC, Area under the curve

\footnotetext{
* Correspondence: okumura@med.u-toyama.ac.jp

${ }^{1}$ Department of Surgery and Science, Graduate School of Medicine and

Pharmaceutical Sciences, University of Toyama, 2630 Sugitani, Toyama

930-0194, Japan

Full list of author information is available at the end of the article
} 


\section{Background}

Recent progress in radical esophagectomies and perioperative adjuvant therapy has facilitated an improved postoperative prognosis, even in patients with advanced esophageal squamous cell carcinoma (ESCC) [1]. However, many of the patients still exhibit postoperative tumor recurrence with a 5-year progression-free survival rate of about $40 \%[2,3]$. Therefore, innovative strategies to predict early postoperative tumor relapse may provide us with a more accurate diagnosis to determine operative indications.

MicroRNAs (miRNAs) are small, single-stranded, noncoding RNAs that play a key role in the initiation and progression of cancer through the post-transcriptional regulation of gene expression [4]. They have also been reported to be potential biomarkers for therapeutic effects and prognoses in cancer patients [5].

In the present study, we investigated the expression profiles of miRNAs in surgically removed ESCC specimens to identify relapse-associated miRNAs.

\section{Methods}

\section{Patients and surgical specimens}

We selected eighty-three consecutive ESCC patients who underwent curative surgery in Toyama University Hospital between 1991 and 2008, excluding 16 cases who died of other causes within 5 years after surgery. Then, we obtained formalin-fixed paraffin-embedded (FFPE) samples of the tumors and their normal counterparts, with adequate tissue size from 36 cases as a training data set. In addition, we obtained frozen samples of surgically resected tumors and their normal counterparts, which had been kept at $-80{ }^{\circ} \mathrm{C}$, from 12 independent ESCC patients who received curative surgery in our hospital between 2008 and 2010 to use as a validation data set. The observation period was calculated from the date of surgery until the patient succumbed to the disease or the last follow-up contact. All cases were staged according to the International Union Against Cancer TNM Classification 7th edition [6].

\section{RNA extraction from FFPE specimens}

Sections $(10 \mu \mathrm{m})$ were prepared from each FFPE specimen. Paraffin was removed by xylene treatment, and the tissues were then washed with ethanol twice to remove the xylene. The tissues were treated with proteinase $\mathrm{K}$ at $37{ }^{\circ} \mathrm{C}$ overnight. Following centrifugation, the supernatant was processed with a silica-based spin column (Toray Industries, Japan) in order to obtain purified total RNA. The degrees of RNA cross-linking and RNA degradation were analyzed by electrophoresis using an Agilent 2100 Bioanalyzer (Agilent Technologies, Santa Clara, CA, USA).
miRNA assays using microarray

miRNA profiling was examined using a Toray 3D-Gene ${ }^{\circ}$ miRNA oligo chip (Toray Industries), on which 885 genes were mounted. The detailed procedure for this experiment has been described previously [7]. The expression level of each miRNA was normalized using the median signal strength for the entire gene in each chip.

\section{RNA extraction from frozen specimens and quantitative RT-PCR analysis for microRNA s}

Frozen specimens were obtained from surgically removed esophagus with Lugol's solution staining. Tumor samples were cut from main part of the tumor, and normal tissues from mucosal epithelia with positive Lugol staining, more than $5 \mathrm{~cm}$ distant from the tumor edge. The sections were also confirmed by a boardcertified pathologist. Total RNA was extracted from frozen specimens using the TRIzol Reagent (Invitrogen, Carlsbad, CA, USA) according to a standard protocol. cDNA was prepared from total RNA samples using the Taq Man microRNA reverse transcription kit on the ABI Prism 7000 real-time PCR system, according to the manufacturer's instructions (Applied Biosystems). Predesigned Taq Man microRNA assays for hsa-miR-574-3p (Assay ID 002349) and RNU6B (Assay ID 001093) were purchased from Applied Biosystems. qRT-PCR was performed using a Taq Man universal PCR master mix, according to the manufacturer's protocol (Applied Biosystems). The microRNA quantities were analyzed in duplicate and normalized against U6B as an internal control. The tumor-to-normal ratio $(\mathrm{T} / \mathrm{N}$ ratio) was calculated based on the miRNA expression levels in each tumor and the corresponding normal counterpart.

\section{Statistical analysis}

All analyses were carried out with JMP 9.0 software (SAS Institute Inc., Cary, NC, USA). The average expression level ( $\mathrm{T} / \mathrm{N}$ ratio) of each miRNA was calculated and $\log 2-$ transformed. Differences in miRNA expression levels between two variables were analyzed by the Student's $t$ test and logistic regression analysis.

Hierarchical clustering analysis was performed with non-supervised Ward's method.

The relationship between the expression of miRNAs and various clinicopathological factors were assessed using the chi-squared test. The Kaplan-Meier method was used to estimate patient survival. Differences in postoperative outcome for the expression of the selected miRNAs were analyzed using the log-rank test. $p<0.01$ was used for significance in microarray analysis with the Student's $t$ test and logistic regression analysis, while $p<0.05$ was used for significance in the chi-squared test and log-rank test. We constructed receiver operating characteristic (ROC) curves and calculated the area under the curve (AUC) to 
evaluate the specificity and sensitivity as a postoperative prognostic predictor.

\section{Results}

\section{Patient information and tumor characteristics}

For a training data set, in 36 cases from which we extracted total RNA from archival FFPE samples, we obtained high-quality RNA of both tumors and corresponding normal esophageal epithelia from 19 patients. The clinical information and tumor characteristics of these patients are shown in Table 1. Among the 19 patients, five patients achieved 5-year disease-free survival with an observation period (average $\pm \mathrm{SD}$ ) of $138.7 \pm 45.1$ months, while 14 patients died of tumor relapse at an observation period (average \pm SD) of $14 \pm$ 9.2 months after surgery. These two groups were referred to as the non-relapse group $(n=5)$ and relapse group $(n=14)$. All patients in the relapse group and three of the five patients in the non-relapse group were males. There were no statistical differences between the relapse and non-relapse group in the other clinicopathological characteristics such as age, tumor location, histological grade, pathologic tumor depth, lymph node metastasis, distant metastasis, TNM stage, lymphatic vessel invasion, or venous invasion. All 19 patients underwent radical surgery with no residual tumors (R0). None of the five patients in the non-relapse group received preoperative adjuvant therapy, while three of the $14(21.4 \%)$ in the relapse group received preoperative chemo- or chemo-radio therapy. One of the five $(20.0 \%)$ patients in the non-relapse group and seven of the $14(50.0 \%)$ patients in the relapse group received postoperative chemo- or chemo-radio therapy. The postoperative observation period (average $\pm \mathrm{SD}$ ) in the non-relapse and relapse groups were $138.7 \pm 45.1$ and $14 \pm 9.2$ months, respectively $(p<0.001)$. In the relapse group, the duration between surgery and tumor relapse (average \pm SD) was $10.0 \pm 8.4$ months. The sites of tumor relapse were; liver: 5, lymph node: 2, local recurrence: 1 , liver and lymph node: 4 , lymph nodes and local recurrence: 2 .

For the validation data set, we obtained high-quality RNA from both tumors and corresponding normal esophageal epithelia from 12 ESCC patients. Eight patients were male and four patients were female, and the average age (average \pm SD) was $63.6 \pm 9.9$ years. All 12 patients underwent radical surgery with no residual tumors (R0). Eight out of 12 patients achieved a 5-year disease-free survival with an observation period (average \pm SD) of $64.6 \pm 18.3$ months, while four patients died of tumor relapse at an observation period (average \pm SD) of $51.2 \pm 27.4$ months after surgery $(p=0.049$, Table 4$)$. These two groups were referred to as the relapse group $(n=4)$ and non-relapse group $(n=8)$.
Table 1 Clinicopathological characteristics of the 19 patients in the training data set

\begin{tabular}{|c|c|c|c|}
\hline & Non-relapse & Relapse & $p$ value \\
\hline Case number & 5 & 14 & \\
\hline Age $($ mean $\pm S D)$ & $68.4 \pm 10.7$ & $61 \pm 9.6$ & 0.111 \\
\hline \multicolumn{4}{|l|}{ Gender } \\
\hline Male & 3 & 14 & \multirow[t]{2}{*}{0.012} \\
\hline Female & 2 & 0 & \\
\hline \multicolumn{4}{|l|}{ Tumor location } \\
\hline Upper/middle thoracic & 1 & 7 & \multirow[t]{2}{*}{0.244} \\
\hline Lower thoracic & 4 & 7 & \\
\hline \multicolumn{4}{|l|}{ Histological grade } \\
\hline Well/moderate & 4 & 13 & \multirow[t]{2}{*}{0.421} \\
\hline Poorly & 1 & 1 & \\
\hline \multicolumn{4}{|l|}{ Pathologic tumor depth } \\
\hline $\mathrm{T} 1-2$ & 3 & 3 & \multirow[t]{2}{*}{0.111} \\
\hline T3-4 & 2 & 11 & \\
\hline \multicolumn{4}{|l|}{ Lymph node metastasis } \\
\hline No & 2 & 3 & \multirow[t]{2}{*}{0.418} \\
\hline $\mathrm{N} 1-3$ & 3 & 11 & \\
\hline \multicolumn{4}{|l|}{ Distant metastasis } \\
\hline MO & 5 & 14 & \multirow[t]{2}{*}{-} \\
\hline M1 & 0 & 0 & \\
\hline \multicolumn{4}{|c|}{ TNM stage (IUAC TNM Classification 7th edition) } \\
\hline $1-2$ & 3 & 4 & \multirow[t]{2}{*}{0.211} \\
\hline $3-4$ & 2 & 10 & \\
\hline \multicolumn{4}{|l|}{ Lymphatic vessel invasion } \\
\hline Negative & 2 & 3 & \multirow[t]{2}{*}{0.418} \\
\hline Positive & 3 & 11 & \\
\hline \multicolumn{4}{|l|}{ Venous invasion } \\
\hline Negative & 3 & 4 & \multirow[t]{2}{*}{0.211} \\
\hline Positive & 2 & 10 & \\
\hline \multicolumn{4}{|l|}{ Curability } \\
\hline RO & 5 & 14 & \multirow[t]{2}{*}{-} \\
\hline R1 & 0 & 0 & \\
\hline Preoperative chemotherapy & 0 & 2 & \multirow[t]{2}{*}{-} \\
\hline $\begin{array}{l}\text { Preoperative chemo radiation } \\
\text { therapy (CRT) }\end{array}$ & 0 & 1 & \\
\hline Postoperative chemotherapy & 0 & 2 & \multirow[t]{2}{*}{-} \\
\hline Postoperative CRT & 1 & 5 & \\
\hline Observation period (month, mean $\pm \mathrm{SD}$ ) & $138.7 \pm 45.1$ & $14 \pm 9.2$ & $<0.001$ \\
\hline $\begin{array}{l}\text { Duration between surgery and tumor } \\
\text { relapse }\end{array}$ & - & $10 \pm 8.4$ & - \\
\hline \multicolumn{4}{|l|}{ Type of tumor relapse } \\
\hline Liver $(H)$ & 0 & 5 & \\
\hline Lymph node (Ly) & 0 & 2 & \\
\hline Local (L) & 0 & 1 & \\
\hline $\mathrm{H}+\mathrm{Ly}$ & 0 & 4 & \\
\hline$L y+L$ & 0 & 2 & \\
\hline
\end{tabular}


The expression of miRNAs in FFPE samples of ESCC tumors detected by microarray

In the 885 miRNAs assessed using the miRNA oligo chip, the signals of 320 miRNAs were detected in all examined samples. Comparisons between the average expression levels of miRNAs in the 19 ESCC tumors and those in the 19 corresponding normal tissues revealed that the expression of 10 miRNAs (miR-16, miR-93, miR-200c, miR-15b, miR-25-3p, miR-34a, miR-181a, miR-107, miR-103a, and miR-151a) were more than twofold higher, while that of another 10 miRNAs (miR-133b, miR-513, miR-1224, miR-30c, miR-1236, miR-378a, miR-550a, miR-675, miR-149, and miR-1973) were more than twofold lower in the tumors than in their normal counterparts with statistical difference (Fig. 1a). The relationship between the expression of these $20 \mathrm{miRNAs}$ in the tumors $(\mathrm{T} / \mathrm{N}$ ratio) and clinicopathological features of the tumors were summarized in Additional file 1: Table S1. The higher expression of miR-200c correlated with progressed TNM Stage $(p=0.038)$ and postoperative tumor relapse $(p=0.038)$. On the other hand, the expression of the other 19 miRNAs in tumors did not show correlation with clinicopathological characteristics of the patients. Hierarchical clustering based on all 320 detected miRNAs did not show any relationship between clusters and postoperative tumor relapse (Fig. 1b).

\section{Differentially expressed miRNAs between patients with and without postoperative tumor relapse}

When the expression ( $\mathrm{T} / \mathrm{N}$ ratio) of miRNAs was compared between relapse $(n=14)$ and non-relapse $(n=5)$ cases using two types of statistical method $(t$ test and logistic regression analysis), the lower expression of miR-574-3p and miR-106b, as well as higher expression of miR-1303, correlated with postoperative tumor relapse with statistical significance $(p<0.01$, Table 2). The Box-and-Whisker plots for these three miRNAs were shown in Fig. 2a.

In addition, the lower expression of other four miRNAs (miR-1203, miR-1909, miR-204, miR-371-3p), and higher expression of miR-886-3p, correlated with

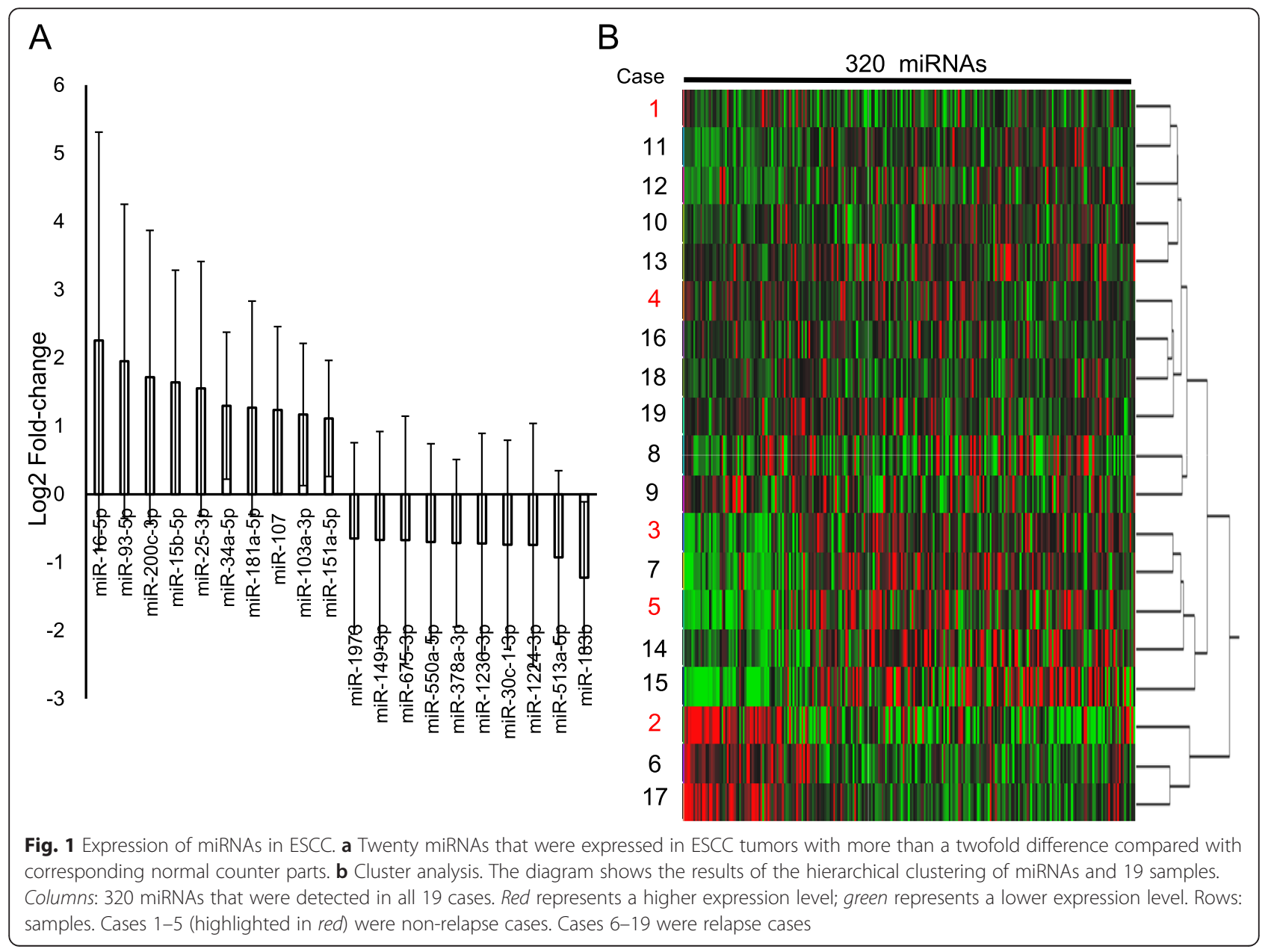


Table 2 Expression of miRNAs associated with postoperative tumor relapse

\begin{tabular}{|c|c|c|c|c|c|c|}
\hline & \multicolumn{2}{|c|}{ Non-Relapse $(n=5)$} & \multicolumn{2}{|c|}{ Relapse $(n=14)$} & \multirow{2}{*}{$\begin{array}{l}t \text { test } \\
p \text { value }\end{array}$} & \multirow{2}{*}{$\begin{array}{l}\text { Logistic regression analysis } \\
p \text { value }\end{array}$} \\
\hline & Average & SD & Average & SD & & \\
\hline miR-574-3p & 0.87 & 0.18 & 0.67 & 0.05 & 0.001 & 0.009 \\
\hline miR-106b & 1.18 & 0.26 & 0.87 & 0.16 & 0.004 & 0.005 \\
\hline miR-1303 & 1.11 & 0.17 & 1.53 & 0.24 & 0.007 & 0.001 \\
\hline miR-1203 & 1.34 & 0.70 & 0.73 & 0.24 & 0.006 & 0.011 \\
\hline miR-1909 & 0.92 & 0.17 & 0.71 & 0.13 & 0.009 & 0.016 \\
\hline miR-204 & 1.10 & 0.35 & 0.76 & 0.23 & 0.016 & 0.033 \\
\hline miR-371-3p & 1.27 & 0.31 & 0.94 & 0.25 & 0.021 & 0.019 \\
\hline miR-886-3p & 0.90 & 0.49 & 1.49 & 0.55 & 0.037 & 0.033 \\
\hline
\end{tabular}

postoperative tumor relapse $(p<0.05$, Table 2$)$. Based on a ROC curve analysis to differentiate patients with relapse from patients without relapse, the cut-off value, the largest AUC value, sensitivity, and specificity for the expression of the top three miRNAs are shown in Table 3.
Based on the cut-off value listed in Table 3, the overall survival rate of the patients with high expression of miR574-3p, low expression of miR-1303 were significantly better (Fig. 2b, d). On the other hand, the expression of miR-106b did not correlate with the overall survival rate of the patients (Fig. 2c).

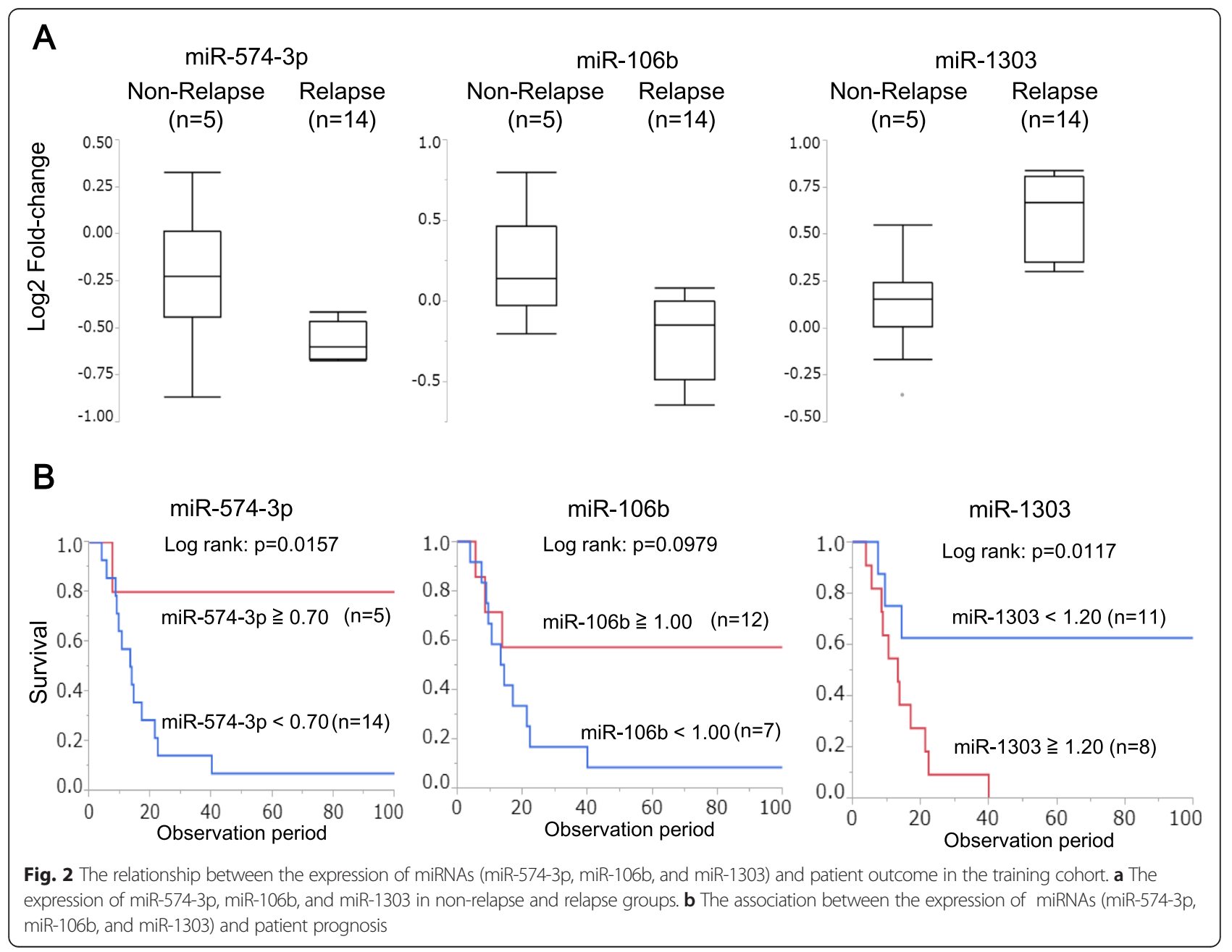


Table 3 Cut-off value for predicting relapse analyzed using receiver-operating characteristic (ROC) curves

\begin{tabular}{lllll}
\hline Name & Cut-off & AUC & Sensitivity & Specificity \\
\hline miR-574-3p & 0.70 & 0.89 & 0.93 & 0.80 \\
miR-106b & 1.00 & 0.89 & 0.79 & 0.80 \\
miR-1303 & 1.20 & 0.94 & 0.86 & 1.00 \\
\hline
\end{tabular}

The expression of miR-574-3p, miR-106b and miR-1303 in frozen samples of ESCC detected by quantitative RT-PCR analysis

Compared with the corresponding normal esophageal mucosa, the expression of miR-574-3p, miR-106b and miR-1303 were upregulated in $8 / 12$ (66.7 \%), 11/12 (91.7\%), and $7 / 12(58.3 \%)$ of the validation set patients (Fig. $3 \mathrm{a}-\mathrm{c})$. When the expression $(\mathrm{T} / \mathrm{N}$ ratio) of miRNAs was compared between relapse $(n=4)$ and non-relapse $(n=8)$ cases, higher expression of miR-574-3p was inversely correlated with tumor relapse $(p=0.029)$, while the expression of miR-106b and miR-1303 did not show correlation with tumor relapse (Table 4). The Box-andWhisker plots for these three miRNAs are shown in Fig. 4a.

The overall survival rate of the patients with high expression of miR-574-3p was significantly better than that of those with low expression $(p=0.004)$, while the expression of miR-106b and miR-1303 did not show correlation with overall survival rate of the patients (Fig. 4b-d).

\section{Discussion}

In the 320 miRNAs assessed using the miRNA oligo chip, the expression of 20 miRNAs were aberrantly expressed in the tumors compared with their normal counterparts, with more than a twofold difference. Among these 20 miRNAs, 13 miRNAs, such as miR-16 [8], miR-93 [9], miR-200c [10], miR-25-3p [11], miR-34a [12], miR-181a [13], miR-107 [14], miR-103a [15], miR151a [16], miR-149 [17], miR-550a [18], miR-378a [19], and miR-30c [20], have been associated with the malignant potential of esophageal cancer.

In addition, the other seven miRNAs, such as miR15b-5p [21], miR-1973 [22], miR-675-3p [23], miR1236-3p [24], miR-1224-3p [25], miR-513a-5p [26], and miR-133b [27], have been associated with the malignant potential of other types of cancer.

These results indicated that the archival FFPE samples were successfully used to identify differentially expressed miRNAs in this study, and suggested the crucial roles of
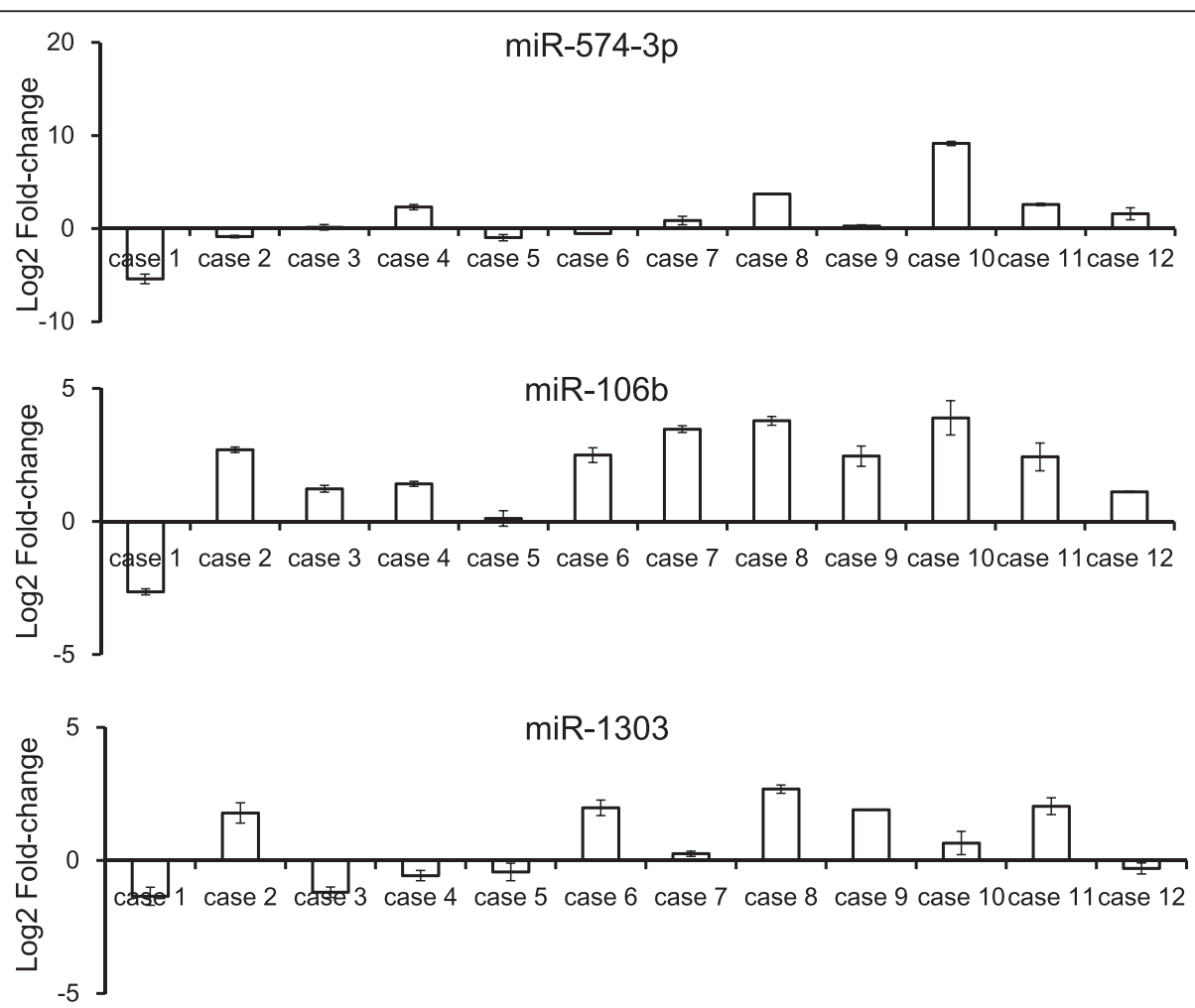

Fig. 3 The expression of miRNAs (miR-574-3p, miR-106b and miR-1303) in ESCC patients in the validation cohort. a The expression (T/N ratio) of miR-574-3p in frozen samples of surgically removed ESCC specimens detected by RT-PCR. $\mathbf{b}$ The expression (T/N ratio) of miR-106b in frozen samples of surgically removed ESCC specimens detected by RT-PCR. c The expression (T/N ratio) of miR-1303 in frozen samples of surgically removed ESCC specimens detected by RT-PCR 
Table 4 Clinicopathological characteristics of the 12 patients in the validation set

\begin{tabular}{|c|c|c|c|}
\hline & Non-relapse & Relapse & $p$ value \\
\hline Case number & 8 & 4 & \\
\hline Age $($ mean $\pm S D)$ & $63.0 \pm 10.3$ & $66.7 \pm 8.0$ & 0.425 \\
\hline \multicolumn{4}{|l|}{ Gender } \\
\hline Male & 4 & 4 & \multirow[t]{2}{*}{0.08} \\
\hline Female & 4 & 0 & \\
\hline \multicolumn{4}{|l|}{ Tumor location } \\
\hline Upper/middle thoracic & 5 & 2 & \multirow[t]{2}{*}{0.67} \\
\hline Lower thoracic & 3 & 2 & \\
\hline \multicolumn{4}{|l|}{ Histological grade } \\
\hline Well/moderate & 7 & 2 & \multirow[t]{2}{*}{0.16} \\
\hline Poorly & 1 & 2 & \\
\hline \multicolumn{4}{|l|}{ Pathologic tumor depth } \\
\hline $\mathrm{T} 1-2$ & 2 & 1 & \multirow[t]{2}{*}{1.00} \\
\hline T3-4 & 6 & 3 & \\
\hline \multicolumn{4}{|l|}{ Lymph node metastasis } \\
\hline No & 3 & 1 & \multirow[t]{2}{*}{0.66} \\
\hline N1-3 & 5 & 3 & \\
\hline \multicolumn{4}{|l|}{ Distant metastasis } \\
\hline MO & 8 & 4 & \multirow[t]{2}{*}{-} \\
\hline M1 & 0 & 0 & \\
\hline \multicolumn{4}{|l|}{ TNM stage } \\
\hline $1-2$ & 3 & 1 & \multirow[t]{2}{*}{0.66} \\
\hline $3-4$ & 5 & 3 & \\
\hline \multicolumn{4}{|l|}{ Lymphatic vessel invasion } \\
\hline Negative & 3 & 1 & \multirow[t]{2}{*}{0.66} \\
\hline Positive & 5 & 3 & \\
\hline \multicolumn{4}{|l|}{ Venous invasion } \\
\hline Negative & 2 & 1 & \multirow[t]{2}{*}{1.00} \\
\hline Positive & 6 & 3 & \\
\hline \multicolumn{4}{|l|}{ Curability } \\
\hline Ro & 8 & 4 & \multirow[t]{2}{*}{-} \\
\hline R1 & 0 & 0 & \\
\hline Preoperative chemotherapy & 5 & 3 & \multirow[t]{2}{*}{-} \\
\hline Preoperative CRT & 0 & 0 & \\
\hline Postoperative chemotherapy & 2 & 3 & \multirow[t]{2}{*}{-} \\
\hline Postoperative CRT & 0 & 0 & \\
\hline $\begin{array}{l}\text { Observation period (month, } \\
\text { mean } \pm S D \text { ) }\end{array}$ & $64.6 \pm 18.3$ & $51.1 \pm 33.6$ & 0.049 \\
\hline $\begin{array}{l}\text { Duration between surgery and } \\
\text { tumor relapse }\end{array}$ & - & $8.8 \pm 2.9$ & - \\
\hline \multicolumn{4}{|l|}{ Type of tumor relapse } \\
\hline Liver $(H)$ & 0 & 2 & \\
\hline Lymph node (Ly) & 0 & 2 & \\
\hline
\end{tabular}

Table 4 Clinicopathological characteristics of the 12 patients in the validation set (Continued)

\begin{tabular}{llll}
\hline miR-574-3p $(<0.7)$ & 1 & 3 & 0.029 \\
miR-574-3p $(\geq 0.7)$ & 7 & 1 & \\
miR-106b $(<1.00)$ & 1 & 1 & 0.576 \\
$\operatorname{miR}-106 b(\geq 1.00)$ & 7 & 3 & \\
$\operatorname{miR}-1303(<1.20)$ & 5 & 2 & 0.576 \\
$\operatorname{miR}-1303(\geq 1.20)$ & 3 & 2 & \\
\hline
\end{tabular}

these miRNAs in the development and progression of ESCC.

The expression profiles of miRNAs have been shown to differentiate molecular subtypes in several types of cancer, such as pancreatic cancer [28] and small cell carcinoma of the esophagus [29]. A previous report from our laboratory has demonstrated that hierarchical clustering based on all 410 detected miRNAs showed two discrete clusters in primary small cell carcinoma of the esophagus, and these two clusters were identical to the two patients groups, i.e., patients with and without postoperative tumor relapse [29]. However, in this present study, hierarchical clustering based on all 320 detected miRNAs did not show a relationship between clusters and postoperative tumor relapse, indicating the need to select a specific gene set to predict postoperative outcomes.

All the 15 miRNAs that were significantly expressed differentially between the relapse and non-relapse groups $(p<0.05)$ have been reported to be either oncogenes [18, 29-36], or tumor suppressors [37-42] in various type of tumors.

In the list of miRNAs, the higher expression of miR574-3p, which showed the most significant inverse association with postoperative tumor relapse $(p=0.001)$, was linked with a significantly better overall survival rate of the patients in the training set.

In the validation set of the patients, higher expression of miR-574-3p was inversely associated with tumor relapse $(p=0.029)$ and a better overall survival rate $(p=0.004)$, further suggesting that the aberrant expression of the miRNAs identified in this study plays key roles in the postoperative outcome of ESCC.

miR-574-3p has been reported to be a tumor suppressor miRNA in various cancers [43]. In gastric cancer, reduced expression of miR-574-3p in tumors and inhibition of cell proliferation, migration, and invasion in miR-574-3p-transfected cancer cells have been reported [37]. In bladder cancer cells, miR-574-3p has been reported to target mesoderm development candidate 1 (MESDC1) miRNA, subsequently inhibiting cell proliferation, migration and invasion ability, and induced cell apoptosis [44]. In prostate cancer, miR-574-3p was 


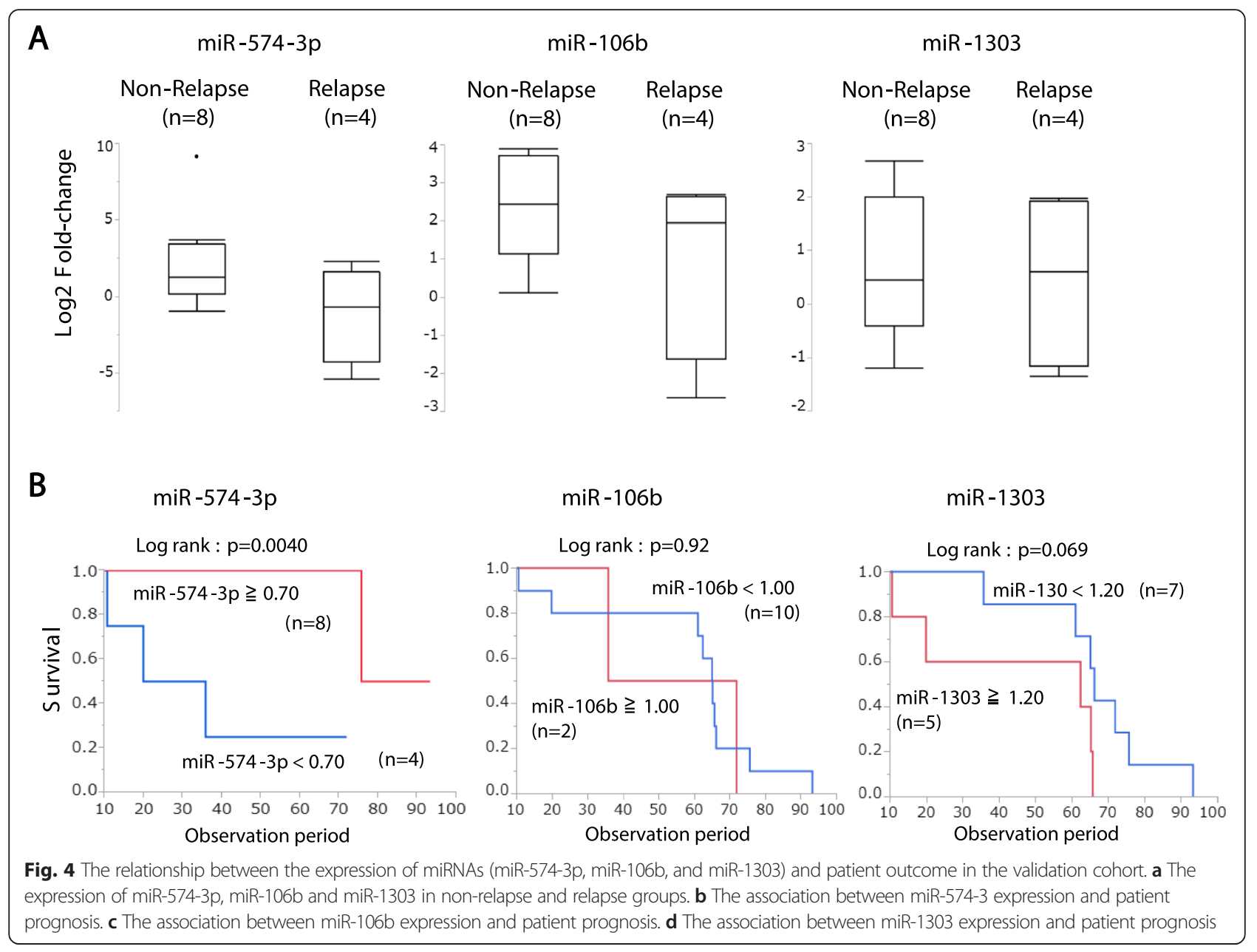

reported to regulate "Wnt signaling" to reduce cell proliferation by targeting epidermal growth factor receptor (EGFR) expression [43]. On the other hand, this is the first report of a correlation between the downregulation of miR-574-3p expression and poor prognosis in patients with ESCC, suggesting the tumor suppressor effects of miR-574-3p in ESCC.

Although molecular targets of miR-574-3p in ESCC have yet to be investigated, the Wnt signaling pathway has been reported to play an important role in progression, metastasis, and invasion in ESCC [45]. Overexpression of EGFR was also associated with aggressive biological behaviors in ESCC [46]. Accordingly, it is possible that miR574-3p targets the Wnt signaling pathway and/or EGFR to suppress malignant features in ESCC as well. Investigations to reveal the biological role of miR-574-3p, such as transfection of ESCC cell lines with miR-574-3p expression vector to assess the regulation of malignant phenotype, may provide us with the basis of the prognostic significance of miR-574-3p. It may also provide us with molecular targets to develop novel diagnostic and/or therapeutic strategies.
In this study, we obtained formalin-fixed paraffinembedded (FFPE) samples of the tumors and their normal counterparts, with adequate tissue size from 36 cases and extracted high-quality RNA from 19 patients. After these sample collection with technical limitation, clinicopathological characteristics of the 19 patients summarized in Table 1 showed distinctive features compared to general population of ESCC patients. For example, higher incidence of postoperative tumor relapse $(14 / 19,73.7 \%)$ was seen and the major type $(9 / 14,64.3 \%)$ of the tumor relapse were hematologic metastasis.

Therefore, it is possible that the pathological $\mathrm{T}$ and $\mathrm{N}$ factor did not correlate with postoperative tumor relapse in our study because of the deviation in the sample collection. Further investigations based on the large-scale collection of samples without deviation is needed to confirm our results.

\section{Conclusions}

Our microarray analysis using the archived FFPE samples of surgically removed ESCC tumors from 19 training set patients identified 8 miRNAs that were differentially expressed between the patients with and without 
postoperative tumor relapse. The higher expression of miR574-3p, which showed the most significant inverse association with postoperative tumor relapse, was significantly associated with better overall survival. Quantitative real-time PCR experiments using frozen samples of ESCC tumors from 12 independent validation set patients confirmed that the higher expression of miR-574-3p was significantly associated with non-tumor relapse and better overall survival.

Although we only examined a small number of the cases, to the best of our knowledge, this is the first study to show the association between the expression of miR574-3p and postoperative outcomes in ESCC patients. Further investigations based on the large-scale collection of samples are awaited to assess the clinical use of miR574-3p as prognostic predictor in patients with ESCC. Molecular biological investigations to define the mechanisms by which miR-574-3p suppresses malignant feature of ESCC using cell lines also provide us with the basis of its prognostic significance and a molecular target to develop novel diagnostic and/or therapeutic strategies.

\section{Additional file}

Additional file 1: Table $\mathbf{S 1}$. The relationship between the expression of the 20 miRNAs in the tumors (T/N ratio) and clinicopathological features of the patients. (XLSX $20 \mathrm{~kb}$ )

\section{Acknowledgements}

Not applicable.

\section{Funding}

This work was supported by JSPS KAKENHI Grant Numbers JP15 K10088 and JP15 K10089.

\section{Availability of data and material}

The authors cannot share the raw data of the microarray analysis because of intellectual property.

\section{Authors' contributions}

TO was involved in the conception and design, informed consent, surgery, experiments, and manuscript writing. HK, TM, SS, and TN were involved in the conception, experiments, and manuscript writing. YS was involved in the conception and design and manuscript writing. All authors read and approved the final manuscript.

\section{Competing interests}

The authors declare that they have no competing interests.

\section{Consent for publication}

Not applicable.

\section{Ethics approval and consent to participate}

Written informed consent was obtained from patients with approval by the Institutional Review Board in the Toyama University Hospital (No.20-75)

\section{Author details}

'Department of Surgery and Science, Graduate School of Medicine and Pharmaceutical Sciences, University of Toyama, 2630 Sugitani, Toyama 930-0194, Japan. ²Department of Nanobio Drug Discovery, Graduate School of Pharmaceutical Sciences, Kyoto University, Kyoto, Japan.

Received: 27 April 2016 Accepted: 17 August 2016

Published online: 26 August 2016

\section{References}

1. Thallinger CM, Raderer M, Hejna M. Esophageal cancer: a critical evaluation of systemic second-line therapy. J Clin Oncol. 2011;29:4709-14.

2. Ando $\mathrm{N}$, Kato $\mathrm{H}$, Igaki $\mathrm{H}$, Shinoda M, Ozawa $\mathrm{S}$, Shimizu $\mathrm{H}$, et al. A randomized trial comparing postoperative adjuvant chemotherapy with cisplatin and 5-fluorouracil versus preoperative chemotherapy for localized advanced squamous cell carcinoma of the thoracic esophagus (JCOG9907). Ann Surg Oncol. 2012;19:68-74. doi:10.1245/s10434-011-2049-9.

3. Hara H, Tahara M, Daiko H, Kato K, Igaki H, Kadowaki S, et al. Phase II feasibility study of preoperative chemotherapy with docetaxel, cisplatin, and fluorouracil for esophageal squamous cell carcinoma. Cancer Sci. 2013;104: 1455-60. doi:10.1111/cas.12274.

4. Baek D, Villén J, Shin C, Camargo FD, Gygi SP, Bartel DP. The impact of microRNAs on protein output. Nature. 2008;455:464-71.

5. Lin RJ, Xiao DW, Liao LD, Chen T, Xie ZF, Huang WZ, et al. MiR-142-3p as a potential prognostic biomarker for esophageal squamous cell carcinoma. J Surg Oncol. 2012;105:175-82. doi:10.1002/jso.22066.

6. Sobin LH, Gospodarowicz M, Wittekind C, editors. TNM Classification of Malignant Tumours, 7th Edition, UICC International Union Against Cancer 2010. Hoboken, NJ: Wiley-Blackwell; 2010.

7. Osawa S, Shimada Y, Sekine S, Okumura T, Nagata T, Fukuoka J, et al. MicroRNA profiling of gastric cancer patients from formalin-fixed paraffin-embedded samples. Oncol Lett. 2011;2:613-9.

8. Zhu Y, Xia Y, Niu H, Chen Y. MiR-16 induced the suppression of cell apoptosis while promote proliferation in esophageal squamous cell carcinoma. Cell Physiol Biochem. 2014;33:1340-8. doi:10.1159/000358701.

9. Ansari MH, Irani S, Edalat H, Amin R, Mohammadi RA. Deregulation of miR-93 and miR-143 in human esophageal cancer. Tumour Biol. 2015;1 [Epub ahead of print].

10. Yu H, Duan B, Jiang L, Lin M, Sheng H, Huang J, et al. Serum miR-200c and clinical outcome of patients with advanced esophageal squamous cancer receiving platinum-based chemotherapy. Am J Transl Res. 2013;6:71-7.

11. Komatsu S, Ichikawa D, Hirajima S, Kawaguchi T, Miyamae M, Okajima W, et al. Plasma microRNA profiles: identification of miR-25 as a novel diagnostic and monitoring biomarker in oesophageal squamous cell carcinoma. $\mathrm{Br} J$ Cancer. 2014:111:1614-24. doi:10.1038/bjc.2014.451.

12. Nie J, Ge X, Geng Y, Cao H, Zhu W, Jiao Y, et al. miR-34a inhibits the migration and invasion of esophageal squamous cell carcinoma by targeting Yin Yang-1. Oncol Rep. 2015;34:311-7. doi:10.3892/or.2015.3962.

13. Xiang Z, Dong X, Sun Q, Li X, Yan B. Clinical significance of up-regulated miR-181a in prognosis and progression of esophageal cancer. Acta Biochim Biophys Sin. 2014;46:1007-10. doi:10.1093/abbs/gmu083.

14. Sharma P, Saraya A, Gupta P, Sharma R. Decreased levels of circulating and tissue miR-107 in human esophageal cancer. Biomarkers. 2013;18:322-30. doi:10.3109/1354750X.2013.781677.

15. Guo $Y$, Chen Z, Zhang L, Zhou F, Shi S, Feng $X$, et al. Distinctive microRNA profiles relating to patient survival in esophageal squamous cell carcinoma. Cancer Res. 2008;68:26-33. doi:10.1158/0008-5472.CAN-06-4418.

16. Gu J, Wang Y, Wu X. MicroRNA in the pathogenesis and prognosis of esophageal cancer. Curr Pharm Des. 2013;19:1292-300.

17. Zhang C, Wang C, Chen X, Yang C, Li K, Wang J, et al. Expression profile of microRNAs in serum: a fingerprint for esophageal squamous cell carcinoma. Clin Chem. 2010;56:1871-9. doi:10.1373/clinchem.2010.147553.

18. Wu C, Li M, Hu C, Duan H. Prognostic role of microRNA polymorphisms in patients with advanced esophageal squamous cell carcinoma receiving platinum-based chemotherapy. Cancer Chemother Pharmacol. 2014:73:335-41. doi:10.1007/s00280-013-2364-x.

19. Hummel R, Sie C, Watson DI, Wang T, Ansar A, Michael MZ, et al. MicroRNA signatures in chemotherapy resistant esophageal cancer cell lines. World J Gastroenterol. 2014;20:14904-12.

20. Zhan C, Yan L, Wang L, Jiang W, Zhang Y, Xi J, et al. Landscape of expression profiles in esophageal carcinoma by The Cancer Genome Atlas data. Dis Esophagus. 2015. doi:10.1111/dote.12416.

21. Hanniford D, Zhong J, Koetz L, Gaziel-Sovran A, Lackaye DJ, Shang S, et al. A miRNA-based signature detected in primary melanoma tissue predicts development of brain metastasis. Clin Cancer Res. 2015;21:4903-12. doi:10.1158/1078-0432.CCR-14-2566

22. El-Awady RA, Hersi F, Al-Tunaiji H, Saleh EM, Abdel-Wahab AH, Al Homssi A, et al. Epigenetics and miRNA as predictive markers and targets for lung cancer chemotherapy. Cancer Biol Ther. 2015;16:1056-70. doi:10.1080/ 15384047.2015.1046023. 
23. He D, Wang J, Zhang C, Shan B, Deng X, Li B, et al. Down-regulation of miR675-5p contributes to tumor progression and development by targeting pro-tumorigenic GPR55 in non-small cell lung cancer. Mol Cancer. 2015;14:73. doi:10.1186/s12943-015-0342-0.

24. Wang Y, Yan S, Liu X, Zhang W, Li Y, Dong R, et al. miR-1236-3p represses the cell migration and invasion abilities by targeting ZEB1 in high-grade serous ovarian carcinoma. Oncol Rep. 2014;31:1905-10. doi:10.3892/or.2014.3046.

25. Qian J, Li R, Wang YY, Shi Y, Luan WK, Tao T, et al. MiR-1224-5p acts as a tumor suppressor by targeting CREB1 in malignant gliomas. Mol Cell Biochem. 2015:403:33-41. doi:10.1007/s11010-015-2334-1.

26. Chen J, Jiang CC, Jin L, Zhang XD. Regulation of PD-L1: a novel role of prosurvival signalling in cancer. Ann Oncol. 2016;27:409-16. doi:10.1093/ annonc/mdv615.

27. Tao J, Wu D, Xu B, Qian W, Li P, Lu Q, et al. microRNA-133 inhibits cell proliferation, migration and invasion in prostate cancer cells by targeting the epidermal growth factor receptor. Oncol Rep. 2012;27:1967-75. doi:10.3892/or.2012.1711

28. Namkung J, Kwon W, Choi Y, Yi SG, Han S, Kang MJ, et al. Molecular subtypes of pancreatic cancer based on miRNA expression profiles have independent prognostic value. J Gastroenterol Hepatol. 2015. doi:10.1111/jgh.13253.

29. Okumura T, Shimada Y, Omura T, Hirano K, Nagata T, Tsukada K. MicroRNA profiles to predict postoperative prognosis in patients with small cell carcinoma of the esophagus. Anticancer Res. 2015;35:719-27.

30. Kan T, Sato F, Ito T, Matsumura N, David S, Cheng Y, et al. The miR-106b-25 polycistron, activated by genomic amplification, functions as an oncogene by suppressing p21 and Bim. Gastroenterology. 2009;136:1689-700.

31. Lerebours F, Cizeron-Clairac G, Susini A, Vacher S, Mouret-Fourme E, Belichard C, et al. miRNA expression profiling of inflammatory breast cancer identifies a 5-miRNA signature predictive of breast tumor aggressiveness. Int J Cancer. 2013;133:1614-23. doi:10.1002/ijc.28171.

32. Östling P, Leivonen SK, Aakula A, Kohonen P, Mäkelä R, Hagman Z, et al. Systematic analysis of microRNAs targeting the androgen receptor in prostate cancer cells. Cancer Res. 2011;71:1956-67. doi:10.1158/0008-5472.

33. Harata $K$, Ishiguro $H$, Kuwabara $Y$, Kimura M, Mitsui A, Ogawa R, et al. MicroRNA-34b has an oncogenic role in esophageal squamous cell carcinoma. Oncol Lett. 2010;1:685-9.

34. Cao J, Song Y, Bi N, Shen J, Liu W, Fan J, et al. DNA methylation-mediated repression of miR-886-3p predicts poor outcome of human small cell lung cancer. Cancer Res. 2013;73:3326-35. doi:10.1158/0008-5472.CAN-12-3055.

35. Guzel E, Karatas OF, Semercioz A, Ekici S, Aykan S, Yentur S, et al. Identification of microRNAs differentially expressed in prostatic secretions of patients with prostate cancer. Int J Cancer. 2015;136:875-9. doi:10.1002/ijc.29054.

36. Pignot G, Cizeron-Clairac G, Vacher S, Susini A, Tozlu S, Vieillefond A, et al. microRNA expression profile in a large series of bladder tumors: identification of a 3-miRNA signature associated with aggressiveness of muscle-invasive bladder cancer. Int J Cancer. 2013;132:2479-91. doi:10.1002/ijc.27949.

37. Su Y, Ni Z, Wang G, Cui J, Wei C, Wang J, et al. Aberrant expression of microRNAs in gastric cancer and biological significance of miR-574-3p. Int Immunopharmacol. 2012;13:468-75. doi:10.1016/j.intimp.2012.05.016.

38. Della Vittoria Scarpati G, Falcetta F, Carlomagno C, Ubezio P, Marchini S, De Stefano A, et al. A specific miRNA signature correlates with complete pathological response to neoadjuvant chemoradiotherapy in locally advanced rectal cancer. Int J Radiat Oncol Biol Phys. 2012;83:1113-9. doi:10.1016/j.jijobp.2011.09.030.

39. Vimalraj S, Miranda PJ, Ramyakrishna B, Selvamurugan N. Regulation of breast cancer and bone metastasis by microRNAs. Dis Markers. 2013;35:369-87. doi:10.1155/2013/451248.

40. Sun $Y$, Zhang T, Wang $C$, Jin $X$, Jia C, Yu S, et al. MiRNA-615-5p functions as a tumor suppressor in pancreatic ductal adenocarcinoma by targeting AKT2. PLoS One. 2015;10, e0119783. doi:10.1371/journal.pone.0119783.

41. Li W, Chang J, Wang S, Liu X, Peng J, Huang D, et al. miRNA-99b-5p suppresses liver metastasis of colorectal cancer by down-regulating mTOR. Oncotarget. 2015;6:24448-62

42. Yang Y, Liu H, Wang $X$, Chen L. Up-regulation of microRNA-664 inhibits cell growth and increases cisplatin sensitivity in cervical cancer. Int J Clin Exp Med. 2015;8:18123-9.

43. Chiyomaru T, Yamamura S, Fukuhara S, Hidaka H, Majid S, Saini S, et al. Genistein up-regulates tumor suppressor microRNA-574-3p in prostate cancer. PLoS One. 2013;8, e58929. doi:10.1371/journal.pone.0058929.

44. Tatarano S, Chiyomaru T, Kawakami K, Enokida H, Yoshino H, Hidaka H, et al. Novel oncogenic function of mesoderm development candidate 1 and its regulation by MiR-574-3p in bladder cancer cell lines. Int J Oncol. 2012;40:951-9.

45. Deng F, Zhou K, Cui W, Liu D, Ma Y. Clinicopathological significance of wnt/ $\beta$-catenin signaling pathway in esophageal squamous cell carcinoma. Int J Clin Exp Pathol. 2015;8:3045-53. eCollection 2015.

46. Lin G, Sun XJ, Han QB, Wang Z, Xu YP, Gu JL, et al. Epidermal growth factor receptor protein overexpression and gene amplification are associated with aggressive biological behaviors of esophageal squamous cell carcinoma. Oncol Lett. 2015;10:901-6.

\section{Submit your next manuscript to BioMed Central and we will help you at every step:}

- We accept pre-submission inquiries

- Our selector tool helps you to find the most relevant journal

- We provide round the clock customer support

- Convenient online submission

- Thorough peer review

- Inclusion in PubMed and all major indexing services

- Maximum visibility for your research

Submit your manuscript at www.biomedcentral.com/submit
( Biomed Central 